\title{
Home, home on the range...
}

\author{
JOHN NEWBY
}

...where the deer and the antelope play ${ }^{1}$. Well, perhaps used to play, if the rangelands of the Sahel and Sahara are anything to go by. Today, the large bird and mammal fauna of this vast region of North Africa is one of the most threatened, in part as a result of livestock development. Drought, desertification, habitat loss and, especially, overexploitation have reduced many species to the verge of extinction, with species such as the addax Addax nasomaculatus, dama gazelle Nanger dama and cheetah Acinonyx jubatus absent from over $95 \%$ of their former ranges (Durant et al., 2014). One species, the scimitar-horned oryx Oryx dammah, is extinct in the wild, and populations of others, such as the Barbary sheep Ammotragus lervia, dorcas gazelle Gazella dorcas, slenderhorned gazelle Gazella leptoceros, Cuvier's gazelle Gazella cuvieri, striped hyaena Hyaena hyaena, ostrich Struthio camelus, and Nubian Neotis nuba and Arabian Ardeotis arabs bustards, are seriously threatened over large parts of their range (IUCN, 2013; BirdLife International, 2014; Newby et al., 2014). Without dedicated programmes and significant funding, once abundant and widely distributed species will dwindle to insignificance. Over the next decade new extinctions cannot be ruled out, with the Critically Endangered addax and dama gazelle most in danger.

Beyond strict protection from illegal or unsustainable offtake as a result of hunting and poaching, and the impacts of processes of a very large and complex scale and nature, such as desertification and climate change, the major longterm challenge facing Sahelo-Saharan species is finding a workable and mutually beneficial balance between their needs and those of the pastoral communities and their livestock that share the same resources of space, pasture, water and shade. There is no doubt of the economic, social and cultural values of pastoralism in the Sahel and Sahara but it is imperative we seek and develop scenarios where pastoralism and its development progress hand in hand with biodiversity conservation and improvements in the status of threatened species, including restoration of habitats and the reintroduction of lost or failing species where necessary. Biodiversity conservation plays a valuable but largely ignored or undervalued role in sustaining pastoralism and increasing its resilience to drought, desertification and climate change. If developed carefully, biodiversity

John Newby Sahara Conservation Fund, Rue des Tigneuses, 1148 L'Isle, Switzerland. E-mail scf@saharaconservation.org

1 From a poem originally penned by Dr Brewster Higley in 1876 before being reworked as the well-known folk song, and state song of Kansas, extolling the virtues of the American rangelands. conservation can also generate complementary income and employment. In this regard, the wildlife of the Sahel and Sahara is no different from a host of other threatened species faced with similar threats of habitat loss and increased occupation and transformation of once wilder lands.

Significant similarities and common ground exist between the arid-land wildlife and pastoral sectors. Traditionally, pastoralism mirrors wildlife in its dependence on access to pastures and plants of high quality, in seasonal movements based on climate, precipitation and the ensuing pasture, and in mobility as an adaptation to unpredictability in the distribution, quantity and quality of grazing. Both sectors share common threats, and possibly benefits, from climate change, depending on the prevailing scenario (IIED, 2013). A drier Sahel could possibly favour the better-adapted wildlife whereas a wetter Sahel would undoubtedly lead to increased pressure from livestock and possibly the expansion of rain-fed agriculture.

Whereas wildlife is, with few notable exceptions (e.g. livestock predation), entirely compatible with and benign to pastoral interests, the inverse is not necessarily true. Competition from livestock, spatially, seasonally and quantitatively, is depriving wildlife of former habitats and pastures, a process that has been facilitated greatly over the past few decades by the tremendous expansion in the number of deep wells and pumping stations. Formerly, many areas of prime grazing, especially during the long, waterless hot season, were unavailable to pastoralists other than on an ephemeral or seasonal basis. As a result of expansion of livestock into these areas, gazelles and antelopes are increasingly confined to poorly accessible marginal areas, where they are doubly prone to the impacts of drought and desertification. Increasingly rare are those areas where human occupancy and livestock numbers still allow cohabitation with wildlife.

Over the past 50-60 years the prime response of governments and the conservation community to the disappearance of Sahelo-Saharan wildlife has been the setting up of invariably large protected areas such as the Ahaggar and Tassili National Parks in Algeria, the Air and Termit Nature Reserves in Niger, and the Ouadi Rimé-Ouadi Achim Game Reserve in Chad. Although suitably vast in area (together these five protected areas total $>360,000 \mathrm{~km}^{2}$ ) to accommodate widely dispersed mobile species, lack of resources, civil strife and inadequate management have resulted in failure to address the root causes of wildlife loss and, especially, the need to find and implement enlightened, integrated management of the wildlife-livestock relationship. Even where effective, protected areas and their wildlife populations are increasingly at risk from isolation and 
fragmentation, with the land between these islands increasingly occupied or degraded, leaving little hope for the establishment of effective wildlife corridors.

Protected areas also offer excellent opportunities for trying novel approaches to integrated wildlife-livestock management. Although not always the case, SaheloSaharan wildlife is generally better off in parks and reserves than in surrounding areas. Protected areas also provide a useful framework to experiment with innovative forms of park management, such as public-private models, local governance, and community-based management. Because of their large size, the reserves also offer the opportunity to work at a scale of high relevancy with respect to ecological, climatic and socio-economic parameters and processes.

Beyond wildlife conservation and the benefits that accrue to the sustainable use and management of natural resources in terms of ecological health, services and stability in the face of threats such as drought, desertification, overgrazing and climate change, improvements in pastoral practices and management are also necessary to maintain productivity, resilience and sustainable livelihoods for pastoralists and to avoid the pitfalls of overgrazing, habitat degradation, and the loss of mobility through sedentarization around wells and pumping stations. Failure to embrace these issues fully will not only lead to reduced pastoral productivity and heightened food insecurity but will also result in outmigration and ecological refugees, unplanned urbanization, and associated crisis management and its related costs. In a region beggared by chronic insecurity and civil strife it is not at all unreasonable to stress the role a healthy and productive environment can play in maintaining stability and peace.

Improvements in the status quo can be brought about through integrated management of wildlife and pastoral resources, better land-use planning and zonation. It is amazing how little analysis there is of impacts on wildlife prior to new well-drilling schemes going ahead, even in gazetted protected areas. Increased inter-sectorial skill development for both wildlife and livestock practitioners and improved communication and cooperation between the ministries and donors responsible for the environment, livestock and wells programmes would also be highly beneficial.

While recognizing a number of these issues, recent gatherings to discuss pastoralism across the Sahelo-Saharan region have failed to fully acknowledge the vital role environmental protection and biodiversity conservation have to play in underpinning and sustaining pastoral development (AFD, 2014a,b). Although the prime concern of all pastoralists is access to water there surely has to be room for improvement and trade-offs that see the concerns of herders addressed without losing the unique natural heritage represented by gazelles, antelopes and even predators such as the cheetah.

As just one prerequisite to improved management, an integrated approach to wildlife inventory and land use has been developed and implemented at several sites in Chad, Niger and Tunisia by the Sahara Conservation Fund through its Pan Sahara Wildlife Survey programme (Wacher \& Newby, 2012). The programme is helping identify wildlife hotspots for priority action, including improved management, protection and zonation. Data collection and analysis is carried out rigorously using proven sampling techniques. Equal effort is spent on the collection of comparable data for livestock numbers and composition, as well as seasonal distribution in relation to wildlife resources and habitat condition.

It is vital that this sort of information reaches the hands of decision-makers. It is equally important that the decisionmakers are willing to listen and consider the impacts of pastoral development on wildlife. Failure to do so will inevitably lead to the disappearance of the remaining gazelles and antelopes, their rightful home on the range totally occupied and quite possibly degraded by growing numbers of camels, cattle, goats and sheep. I'm not against livestock in reasonable numbers but would certainly prefer a home 'where the buffalo roam and the deer and the antelope play' alongside those camels and goats if possible.

\section{References}

AfD (Agence Francaise Développement) (2014a) Declaration de N'Djamena. Http://www.afd.fr/webdav/site/afd/shared/PORTAILS/ PAYS/TCHAD/PDF/D\%C3\%A9claration\%2ode\%20N\%27Djam\% C3\%A9na\%2otrilingue.pdf [accessed 15 February 2014].

AfD (Agence Francaise Développement) (2014b) La Politique Sectorielle du Pastoralisme au Tchad: Quelles orientations? Http:// www.afd.fr/webdav/site/afd/shared/PORTAILS/PAYS/TCHAD/ PDF/Actes\%2odu\%2ocolloque_pasto_\%2oTchad.pdf [accessed 15 February 2014].

Birdifie International (2014) Nubian Bustard Neotis nuba. Http://www.birdlife.org/datazone/speciesfactsheet.php?id=2763 [accessed 17 February 2014]

Durant, S.M., Wacher, T., Bashir, S., Woodroffe, R., De Ornellas, P., Ransom, C. et al. (2014) Fiddling in biodiversity hotspots while deserts burn? Collapse of the Sahara's megafauna. Diversity and Distributions, 20, 114-122.

IIED (International Institute for Environment and Development) (2013) Global Public Policy Narratives on the Drylands and Pastoralism. Http://pubs.iied.org/pdfs/1004oIIED.pdf [accessed 19 July 2013].

IUCN (2013) IUCN Red List of Threatened Species v. 2013.2. Http://www.iucnredlist.org [accessed 16 February 2014].

Newby., J., Wacher, T., Durant, S.M., Pettorelli, N. \& Gilbert, T. (2014) The status and distribution of the antelopes and gazelles of the Sahara and bordering Sahelian grasslands. In Antelope Conservation in the 21st Century: From Diagnosis to Action (ed. J. Bro-Jorgensen), in press. Wiley-Blackwell, Oxford, UK.

SCF (Sahara Conservation Fund) (2014) Reports. Http://www. saharaconservation.org/?-Reports-\#SCF\%2oPan\%20Sahara\% 20Wildlife\%20Survey [accessed 15 February 2014].

WACher, T. \& Newby, J. (2012) Summary of Results and Achievements of the Pilot Phase of the Pan Sahara Wildlife Survey 2009-2012. Sahara Conservation Fund Pan Sahara Wildlife Survey Technical Report 12. Sahara Conservation Fund, L'Isle, Switzerland. 